\title{
Comparison of total phenolic and flavonoids contents in Malaysian propolis extract with two different extraction solvents
}

\author{
Siti U. Mokhtar' ${ }^{*}$, H'ng S. Hooi ${ }^{1}$, Darlene T. T. Lene ${ }^{1}$, S. Jayaraman ${ }^{1}$ \\ ${ }^{1}$ Faculty of Chemical and Process Engineering Technology, Universiti Malaysia Pahang, \\ 26300 Kuantan, Pahang, Malaysia \\ Email: umairah@ump.edu.my*
}

\begin{abstract}
This study was aimed to obtain propolis extracts by using two different solvents which are ethanol and water via maceration method and to evaluate the total phenolic and flavonoid components of the extracts. Optimization of the extraction process was done by using different solvents and sampleto-solvent ratio. The ethanolic and water extracts were analysed for the determination of Total Phenolic Content (TPC) and Total Flavonoid Content (TFC) by using Folin-Ciocalteu colorimetric method and Aluminimum chloride method, respectively. Based on sample-to-solvent ratio, it showed that 1:10 gave the highest percentage yield of extracts compared to other ratio for both solvents. The resulting ethanolic extract contains high phenolic and flavonoids content compared to water extract. The result showed that sample-to-solvent ratio of 1:5 gave highest TPC and TFC in ethanolic extract which are 29.09 and $7.75 \mathrm{mg} \mathrm{GAE} / \mathrm{g}$, respectively. In conclusion, this study revealed that ethanol is the best extraction solvent to be used for propolis extraction compared to water. It is also demonstrated that higher volume of solvent does not leads to high values of TPC and TFC. The optimum extraction parameters and conditions are necessary to be obtained in order to extract high TPC and TFC.
\end{abstract}

Keywords - propolis, Folin-Ciocalteu, maceration, phenolic, flavonoids.

\section{INTRODUCTION}

Propolis, known as bee glue [1], is a natural, sticky resinous, balsamic, dark yellow to brown colored and strongly adhesive bee product [2]. Generally, it serves as a substance to protect the bee hive from invaders while providing a disinfecting environment for the bees to lay their eggs [3]. A crude propolis generally contains $50 \%$ resin, $30 \%$ wax, $5 \%$ pollen, $10 \%$ aromatic oils and $5 \%$ other organic residues [4]. The colour and chemical composition of propolis are highly influenced by its geographical origin and the types of plant the bees accessed [5]. Thus, the propolis collected by the bees from different types of plant at different location may have colours vary from one another. The colours may differ from yellowish green to red and to dark brown and it is influenced by its age [6].

In Malaysia, the number of stingless bee species varies between 17 to 32 species depending on the study areas [7-9]. Five species of stingless bee and unidentified species were found in a bee farm located in the state of Kelantan, Malaysia [10]. The species were Trigona (Geniotrigona) thoracica, Trigona (Heterotrigona) itama, Trigona (Lepidotrigona) terminata, Trigona (Lisotrigona) scintillans 
and Trigona (Tetragonula) laeviceps. However, until now, there are only several preliminary studies were performed on the composition and biological activity of Malaysia propolis from stingless bee.

Generally, propolis has been reported to have numerous biological activities, for example, antibacterial, antiviral, antitumor, anti-inflammatory, anticancer and antifungal properties [4]. The chemical composition of propolis is complex and variable, being related to the vegetation of the region visited by bees. The active components present in propolis that result in all these biological activities including phenolic acids, flavonoids, terpenes and sequiterpenes [11]. The presence of these biologically active compounds in propolis has given a great impact in the medical field especially in the development of drug. Due to its popularity in the treatment of various disease and its medicinal properties since the ancient times, propolis has been exposed to intense pharmacological studies in the last few decades.

In this study, an extraction method was conducted to extract propolis of Trigona Thoracica species with two different extraction solvents and different sample-to-solvent ratio. Then, the total phenolic and flavonoid contents of propolis extract were determined by Folin-Ciocalteu method and aluminium nitrate method, respectively. It is expected that there will be different amount of phenolic and flavonoids been extracted by different solvents of same propolis species.

\section{MATERIALS AND METHODS}

\subsection{Chemicals and reagents}

95\% of industrial grade ethanol which was used as an extraction solvent was purchased from Merck (Malaysia). All analytical grade chemicals used in the UV-Vis spectrophotometer such as 2 N Folinciocalteu reagent, sodium carbonate anhydrous powder, gallic acid, aluminium chloride anhydrous powder, $5 \mathrm{~mol} / \mathrm{L}$ potassium acetate and quercetin were purchased from Sigma-Aldrich (St. Louis, US). The propolis sample was stored in a chiller at $-4{ }^{\circ} \mathrm{C}$.

\subsection{Sample collection and extraction method}

Propolis of Trigona Thoracica species that was produced by a stingless bee farm was obtained from Kelantan Biotech Corporation. The crude propolis was crushed into smaller pieces and then grinded to powder by using mortar and pestle. The extraction of propolis was carried out according to a method performed by previous studies with slight modifications [12,13]. A $20 \mathrm{~g}$ of fine propolis powder was weighed using a weighing balance. The propolis powder was mixed with $200 \mathrm{~mL}$ of $70 \%$ ethanol in a conical flask in fume hood. The conical flask was covered with aluminium foil and the mixture was continuously shaken for 7 days in an incubator shaker at room temperature of approximately $28{ }^{\circ} \mathrm{C}$ at $70 \mathrm{rpm}$. After the incubation, the extracts were filtered using Whatman filter paper No.1 with diameter of $185 \mathrm{~mm}$ and filter funnel. The subsequent filtrate was then evaporated off using a rotary evaporator at a rotation speed of about $170 \mathrm{rpm}$ with temperature of $60{ }^{\circ} \mathrm{C}$ and set vacuum pressure of about 995 $\mathrm{hPa}$ to remove all the ethanol content inside the filtrate. A resultant concentrated propolis extracts were then kept in a $-80^{\circ} \mathrm{C}$ freezer for 1 day as a preparation for freeze drying process. They were freeze dried under the conditions with the vacuum pressure of $\pm 200 \mathrm{mT}$ and a temperature of $-40{ }^{\circ} \mathrm{C}$. This step was used to assist in the formation of dried propolis powder. The same procedures were repeated with water as the extraction solvent. 
Dry propolis extract powder was obtained after the freeze drying process. The weight of the dry propolis extract powder gained was weighed for the purpose of determining the percentage yield of extraction. In this study, the extraction yield of propolis was calculated based on the initial weight of raw propolis and the weight of propolis extract gained as stated in equation 2.1:

The extraction yield of propolis was calculated as below:

$$
\begin{gathered}
\text { Extraction yield of propolis }=(\mathrm{Pe} / \mathrm{Pi}) \times 100 \% \\
\text { Where } \mathrm{Pe}=\text { Weight of propolis extract gained } \\
\mathrm{Pi}=\text { Initial weight of raw propolis }
\end{gathered}
$$

For analysis purposes, the dry propolis extracts were then diluted with $70 \%$ ethanol and kept in $-4{ }^{\circ} \mathrm{C}$ chiller.

\subsection{Optimization of extraction method}

Extraction time, temperature, solvent composition and sample-to-solvent-ratio are among the major factors that can influence the efficiency of an extraction process. In this study, the maceration method was optimized by adjusting the sample-to-solvent ratio and type of extraction solvents. In order to obtain the optimum sample-to-solvent ratio for this study, three different sample-to-solvent ratios (1:5, 1:10 and 1:15) were used in water and ethanol propolis extract as shown in Table 1.

Table 1 Three different sample-to-solvent ratio

\begin{tabular}{ccc}
\hline $\begin{array}{c}\text { Amount of raw } \\
\text { propolis }(\mathrm{g})\end{array}$ & $\begin{array}{c}\text { Volume of solvent } \\
(\mathrm{mL})\end{array}$ & $\begin{array}{c}\text { Sample-to-solvent } \\
\text { ratio }\end{array}$ \\
\hline 20 & 100 & $1: 5$ \\
20 & 200 & $1: 10$ \\
20 & 300 & $1: 15$ \\
\hline
\end{tabular}

\subsection{Determination of total phenolic content by UV-Vis Spectrophotometry}

In the determination of total phenolic content (TPC), a stock standard solution of gallic acid with the concentration of $800 \mu \mathrm{g} / \mathrm{mL}$ was prepared by dissolving $0.08 \mathrm{~g}$ of gallic acid standard powder in $95 \%$ of ethanol in a volumetric flask. Then, different concentration of standards in range of 50 to $500 \mu \mathrm{g} / \mathrm{mL}$ were prepared to obtain a standard calibration curve. Two blanks were prepared by using ethanol. For each sample, $200 \mu \mathrm{L}$ of extract was mixed with $1 \mathrm{~mL}$ of Folin-Ciocalteu reagent and $1 \mathrm{~mL}$ of $10 \%$ of sodium carbonate was added after 3 minutes. The use of the Folin-ciocalteu reagent is for the quantification of total phenolics in the sample [14] while the sodium carbonate is an alkali which helps to speed up the oxidation reaction of phenols [15] and the volume was made up to $10 \mathrm{~mL}$ with ultrapure water. The mixture was left for incubation for 90 minutes at a temperature of $23{ }^{\circ} \mathrm{C}$ in the dark and the absorbance was measured at $725 \mathrm{~nm}$ in a UV-Vis spectrophotometer. The result obtained was calculated by using a gallic acid standard calibration curve. The total phenolics were expressed as $\mathrm{mg}$ Gallic Acid equivalents (GAE)/g. 


\subsection{Determination of total flavonoids content by UV-Vis spectrophotometry}

The total flavonoid contents of propolis extract was determined by using the aluminium chloride colorimetric method [17]. For the analysis of the flavonoids content, a stock solution of quercetin as standard solution with concentration of $400 \mu \mathrm{g} / \mathrm{mL}$ was prepared and followed by the standard calibration solution which in range of 25 to $250 \mu \mathrm{g} / \mathrm{mL}$ were prepared according to the previous method with slight modifications [16].

Then, a $0.5 \mathrm{~mL}$ of extract was mixed with approximately $1.5 \mathrm{~mL}$ of ethanol, $0.1 \mathrm{~mL}$ of $10 \%$ aluminium chloride, $0.1 \mathrm{~mL}$ of $1 \mathrm{~mol} / \mathrm{L}$ potassium acetate and $2.8 \mathrm{~mL}$ of water. The mixtures were left for incubation at room temperature for about 30 minutes and the absorbance of the reaction mixtures was measured at $415 \mathrm{~nm}$ in UV-Vis spectrophotometer. The obtained value was compared with the quercetin standard calibration. The experiment was repeated in triplicate.

\section{RESULTS AND DISCUSSION}

\subsection{Propolis extract yield}

From the extraction, it can be seen that the colour turned to reddish brown as the propolis was dissolved in ethanol or water. Formation of dried propolis extract occurred after the freeze-drying process for 2 days and gave pale yellow colour.

The formation of dry propolis extract powder was due to the sublimation process happened in the freeze dryer where the water in the frozen propolis extract was sublimated and removed under an extreme temperature and pressure through the primary and secondary drying phase [18].

The dry propolis extracts obtained by using different sample-to-solvent ratio were weighed and recorded. The values in Table 2 shows the percentage of yield of propolis extract according to sampleto-solvent ratio by both solvents.

Table 2 Percentage yield of propolis

\begin{tabular}{lcc}
\hline Solvent & Sample-to-solvent ratio & Percentage yield $(\%)$ \\
\hline Ethanol & $1: 5$ & 5.79 \\
& $1: 10$ & 10.67 \\
& $1: 15$ & 4.20 \\
\hline Water & $1: 5$ & 5.95 \\
& $1: 10$ & 9.05 \\
& $1: 15$ & 7.16 \\
\hline
\end{tabular}

Water and ethanolic extracted propolis gives the highest percentage of yield at the ratio of 1:10 which were $9.05 \%$ and $10.67 \%$, respectively. This indicates that the sample-to-solvent ratio larger than this value is not necessary at all which is supported by previous studies [19] [20].

Based on Table 2, it shows that the percentage yield of water extracted propolis with the sample-tosolvent ratio of 1:5 and 1:15 were greater than that of propolis extracted using ethanol. This may be due to the removal of much of the moisture content in the ethanolic extract of propolis through the rotary evaporation which results in a smaller volume of propolis extract to be freeze dried. However, 
extraction of propolis using ethanol shows a higher percentage yield as compared to the water in the sample-to-solvent ratio of 1:10. This indicates that ethanol is a better extraction solvent than the water in this optimum ratio since it produces the best yield. The difference in the extraction yield is claimed to be due to the properties of ethanol as an organic solvent which tends to dissolve most of the propolis content [12].

In fact, the propolis content and extraction yield may also differ due to differences in the origin of propolis, bees' types, food resources and harvest time [21-23]. Water gives a lower extraction yield compare to ethanol because it is a polar solvent whereas the ethanol, propyl alcohol and acetone are included as less polar solvents [13]. Water dissolves a small part of propolis components, approximately $10 \%$ of its weight, whereas $70 \%$ ethanol may dissolve $50-70 \%$ of it, depending on the amount of- wax [24].

\subsection{Determination of total phenolic content}

Different sample-to-solvent ratio of the extracts were analysed for their beneficial properties which is total phenolic content by using the UV-Vis spectrophotometer at the wavelength of $725 \mathrm{~nm}$. Figure 2 depicted the standard calibration curve of gallic acid with concentration of 50 to $500 \mu \mathrm{g} / \mathrm{mL}$. It shown a good linearity of concentration and the absorbance with correlation coefficient $\left(\mathrm{r}^{2}\right)$ is 0.9889 . By using the equation of standard calibration curve, the TPC for each sample was calculated and expressed in $\mathrm{mg} \mathrm{GAE} / \mathrm{mg}$. The TPC play an important role as primary antioxidants or free radical scavengers.

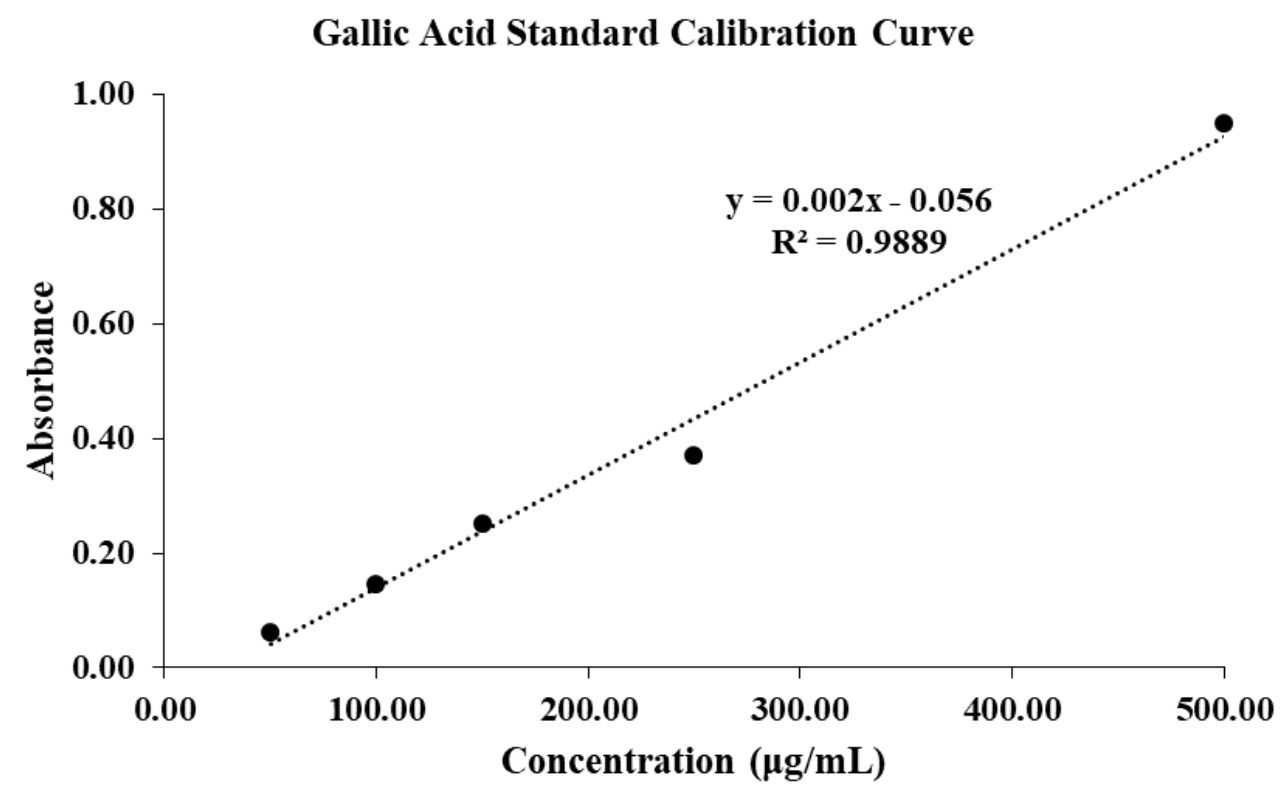

Figure 2: Standard calibration curve of gallic acid 


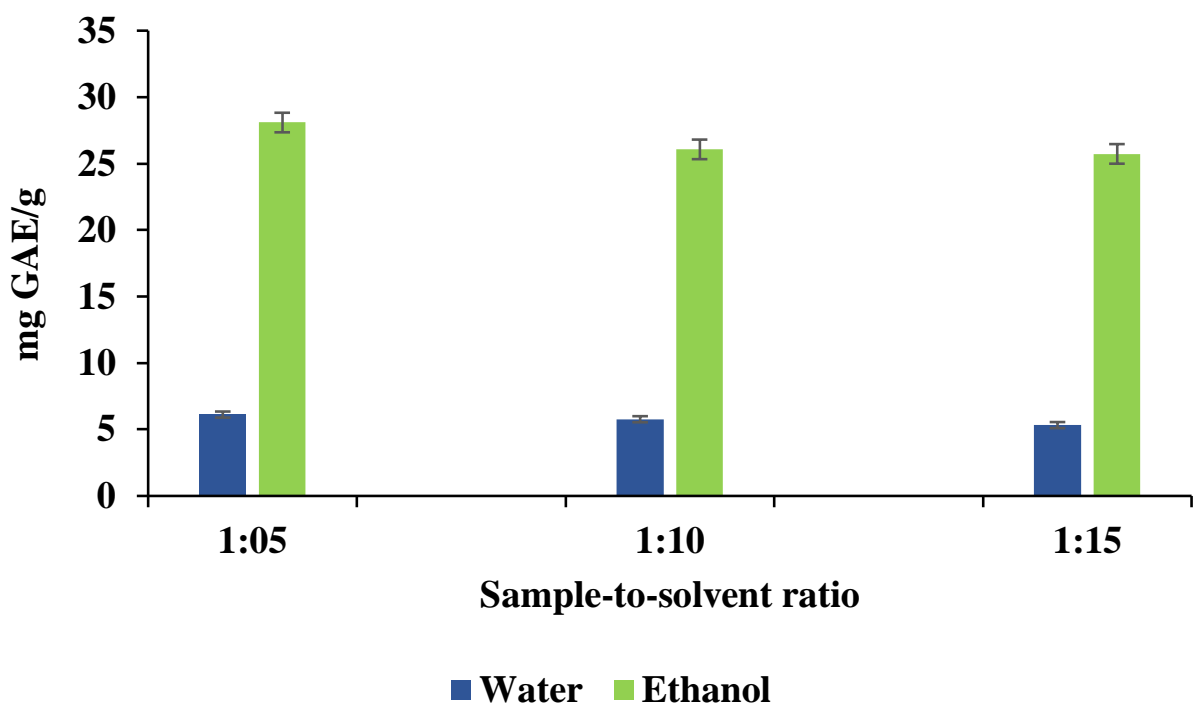

Figure 3: Total phenolic contents (TPC) of propolis extracted by water and ethanol

Based on the result obtained, the TPC was measured and displayed in Figure 3. It can be seen that a low sample-to-solvent ratio was found to be favourable in extraction of the phenolic compounds as the sample-to-solvent ratio of 1:5 produced the best yield of TPC with $28.09 \mathrm{mg} \mathrm{GAE} / \mathrm{g}$ at a wavelength of $725 \mathrm{~nm}$ for ethanolic extract. The result followed by 1:10 (26.07 mg GAE/g) and 1:15 (25.73 mg $\mathrm{GAE} / \mathrm{g}$ ). However, this observation is not in accordance with the mass transfer principle at which the driving force during the mass transfer process is considered to be the concentration gradient between the sample and solvent. It is stated that the concentration gradient is greater when there is a higher sample-to-solvent ratio which eventually results in the increasing of diffusion rate which allows a better phenolic compound yield [25] [26]. The difference in the result obtained from the previous study may be due to the possibility of the propolis not properly dissolved in the sample-to-solvent ratio of 1:15 and the extraction was stopped when an equilibrium was reached [27].

From the result, it revealed that ethanol is more favourable in the extraction of the phenolic compound as compared to the water. The difference in the TPC may be due to the properties of ethanol which acts as an organic solvent that tends to dissolve most of the compounds present in the propolis [12]. Besides that, the properties of water which acts as a polar solvent also dissolve a very little amount of propolis constituents as it has the ability to dissolve the polar compounds only and does not favors the extraction of less polar compounds such as phenolic compounds. Therefore, this leads to a smaller amount of total phenolic contents obtained.

From Figure 3, the TPC of water extracted propolis decreases with the increasing propolis to solvent ratio from 1:5, 1:10 and 1:15. The TPC was the highest $(6.12 \mathrm{mg} \mathrm{GAE} / \mathrm{g})$ when the propolis to solvent ratio was $1: 5$ followed by $5.77 \mathrm{mg} \mathrm{GAE} / \mathrm{g}$ and $5.33 \mathrm{mg} \mathrm{GAE} / \mathrm{g}$ when the propolis to solvent ratio were 1:10 and 1:15, respectively. However, in other study, it confirmed that phenolics extracted of date seeds with water increased from $2.5 \mathrm{~g}$ to $100 \mathrm{~g}$ with increasing solvent ratio to the 60:1 [26]. In comparison with the TPC of propolis from previous study on the species of Trigona Itama and Trigona Thoracica, which are $56.90 \mu \mathrm{g} / \mathrm{mL}$ and $29.10 \mu \mathrm{g} / \mathrm{mL}$, respectively, it revealed that Trigona Itama possesses relatively higher TPC compared to Trigona Throracica [16]. 


\section{Determination of total flavonoid content}

As can be seen in Figure 4, a standard calibration curve of quercetin was obtained from a wide range concentration of quercetin $(25-250 \mu \mathrm{g} / \mathrm{mL})$. An excellent linearity, $r^{2}(0.9978)$ of absorbance versus concentration with equation, $y=0.0063 \mathrm{x}+0.0014$ was obtained. Thus, by using this equation, TFC of the extract was calculated and expressed in $\mathrm{mg} \mathrm{QE} / \mathrm{g}$.

Water and ethanolic extracted propolis showed a decrease in the amount of TFC with an increase of sample-to-solvent ratio as shown in Figure 5. This is in contrast to the mass transfer principle which was proven by Wong and his co-researchers [25]. The mass transfer principle indicated that a higher sample-to-solvent ratio will show an increase in total flavones and flavonols.

In this study, ethanolic extracted propolis showed the highest amount of total flavonoids compared to water extracted propolis. Based on Figure 5, it can be seen that sample-to-solvent ratio of 1:5 of ethanolic extract shows the highest total flavonoids content of $7.85 \mathrm{mg}$ Quercetin Equivalent $(\mathrm{QE}) / \mathrm{g}$ while the ratio of $1: 10$ shows the least content of $7.25 \mathrm{mg} \mathrm{QE} / \mathrm{g}$.

\section{Quercetin Standard Calibration Curve}

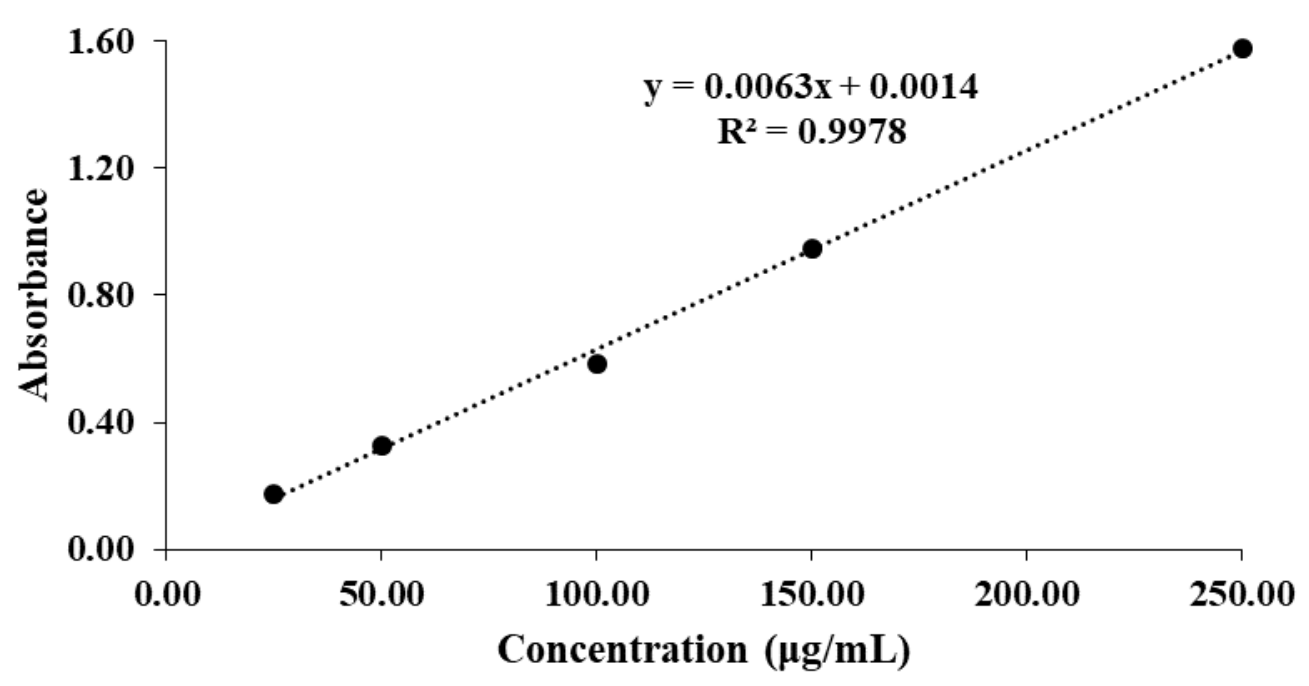

Figure 4: Standard calibration curve of quercetin

For water extracted propolis, it shown that the highest of total flavonoid content was $3.33 \mathrm{mg}$ QE/g when the propolis to solvent ratio was $1: 5$, followed by $2.81 \mathrm{mg} \mathrm{QE} / \mathrm{g}$ and $2.36 \mathrm{mg} \mathrm{QE} / \mathrm{g}$ when the propolis to solvent ratio were $1: 10$ and $1: 15$, respectively. Contents of flavonoids and other phenolic substances have been suggested to play a preventive role in the development of cancer and heart disease [28]. 


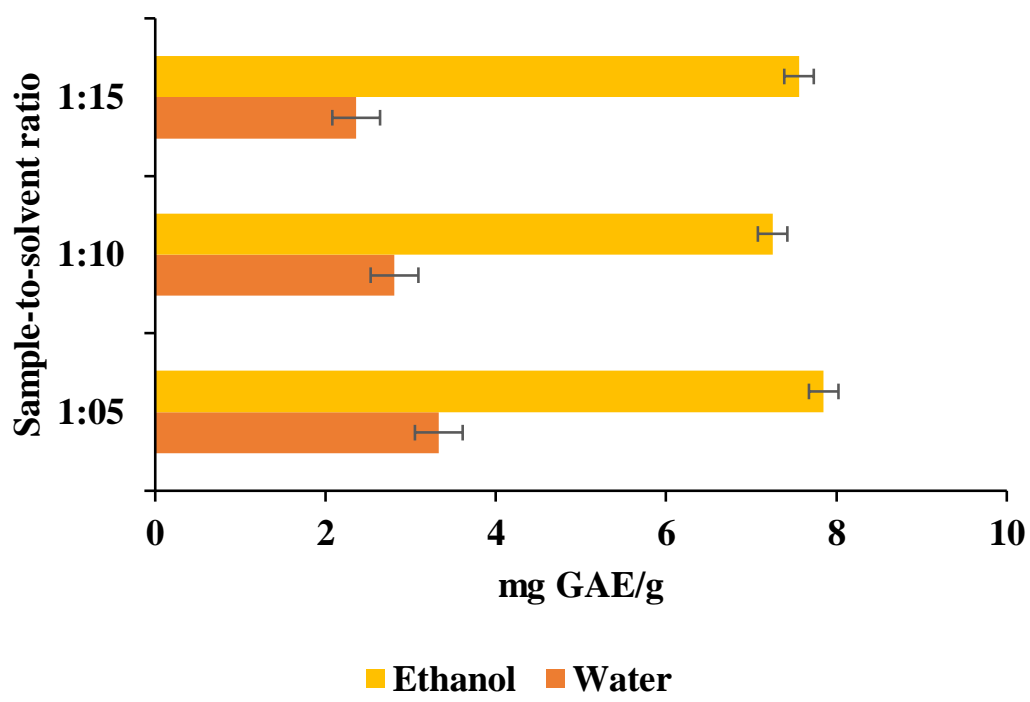

Figure 5: Total flavonoid contents (TFC) of propolis extracted by water and ethanol

\section{CONCLUSION}

This study shows that a maceration method was successfully performed by using two different solvents which are water and ethanol to extract phenolic and flavonoids compounds from propolis. The sampleto-solvent ratio was investigated to obtain an optimum volume of propolis sample and the best volume of solvent for the extraction method. In this work, the optimum ratio that produced high percentage yield of extracts is 1:10 while the best extraction solvent is ethanol. The findings showed ethanolic extract produce high TPC and TFC compared to water. This study can be used as preliminary study and further investigations are needed to be performed since the propolis could be beneficial as alternative medicinal product. Analysis for phytochemical screening by advanced methods are necessary to investigate the active compounds possesses by the propolis.

\section{ACKNOWLEDGEMENT}

This article is fully supported by Internal Grant of University Malaysia Pahang (RDU1703114). The authors are grateful to the Program of Engineering Technology Manufacturing (Pharmaceutical), Faculty of Chemical and Process Engineering Technology and Kelantan Biotech Corporation for material support and technical assistance. 


\section{REFERENCES}

[1] Bogdanov, S., Propolis: Composition, Health, Medicine: A Review. 1st ed. [ebook] Bee Product Science, pp.1-42. Available at: http://www.beehexagon.net/files/file/fileE/Health/PropolisBookReview.pdf [Accessed 11 May 2017], 2016.

[2] Sarıçoban, C. \& Yerlikaya, S., "As a protective material: Propolis". Journal of Agroalimentary Processes and Technologies 22(2): 56-63, 2016.

[3] Park, Y., Paredes-Guzman, J., Aguiar, C., Alencar, S. and Fujiwara, F., "Chemical constituents in Baccharis dracunculifoliaas the main botanical origin of southeastern Brazilian propolis". Journal of Agricultural and Food Chemistry 52(5): 1100-1103, 2004.

[4] Sforcin, J. and Bankova, V., "Propolis: Is there a potential for the development of new drugs?". Journal of Ethnopharmacology 133(2): 253-260, 2011.

[5] De Zordi, N., Cortesi, A., Kikic, I., Moneghini, M., Solinas, D., Innocenti, G., Portolan, A., Baratto, G. and Dall'Acqua, S., "The supercritical carbon dioxide extraction of polyphenols from Propolis: A central composite design approach". The Journal of Supercritical Fluids 95: 491-498, 2014.

[6] Bankova, V.S., Castro, S.L.D. \& Marcucci, M.C., "Propolis: recent advances in chemistry and plant origin". Apidologie 31(1): 3-15, 2000.

[7] Schwarz, H., "The Indo-Malayan species of Trigona”. [Bulletin] The American Museum of Natural History, Volume 76. New York, 233-242, 1939.

[8] Mohd, N., Said Sajap, A., Jajuli, R., Fahimee Jaapar, M. and Suri, R., "Conservation and sustainable utilization of stingless bees for pollination services in agricultural ecosystems in Malaysia", Proceeding of International Seminar on Enhancement of Functional Biodiversity Relevant to Sustainable Food Production in ASPAC. 2010.

[9] Salim, H., Dzulkiply, A., Harrison, R., Fletcher, C., Kassim, A. and Potts, M., "Stingless bee (hymenoptera: Apidae: Meliponini) diversity in dipterocarp forest reserves in Peninsular Malaysia". 1st ed. [ebook] Singapore: The Raffles Bulletin of Zoology, 213-219. Available at: https://www.researchgate.net/publication/236179297_Stingless_bee_hymenoptera_Apidae_Meliponi ni_diversity_in_dipterocarp_forest_reserves_in_Peninsular_Malaysia [Accessed 1 Dec. 2017].

[10] Kelly, N., Farisya, M. S. N., Kumara, T. K. \& Marcela, P., "Species Diversity and External Nest Characteristics of Stingless Bees in Meliponiculture". Pertanika Journal of Tropical Agricultural Science 37(3): 293 - 298. 2014.

[11] Ito, J., Chang, F., Wang, H., Park, Y., Ikegaki, M., Kilgore, N. and Lee, K., "Anti-AIDS agents. 48. 1 anti-HIV activity of moronic acid derivatives and the new melliferone-related triterpenoid isolated from Brazilian propolis”. Journal of Natural Products 64(10): 1278-1281. 2001.

[12] Pujirahayu, N., Ritonga, H. \& Uslinawaty, Z., "Properties and Flavonoids Content in Propolis of some extraction method of raw propolis". International Journal of Pharmacy and Pharmaceutical Sciences 6(6): 338-340. 2014. 
[13] Mageretha, I., Fatma Suniarti, D., Herda, E. and Alim Mas'ud, Z., "Optimization and Comparative Study of Different Extraction Methods of Biologically Active Compounds of Indonesian Propolis Trigona spp". Journal of Natural Products 5: 233-242. 2012.

[14] Maurya, S. and Singh, D., "Quantitative analysis of total phenolic content in Adhatoda Vasica Nees extracts”. International Journal of PharmTech Research 2(4): 2403-2406. 2010.

[15] Cicco, N. and Lattanzio, V., "The influence of initial carbonate concentration on the folinciocalteu micro-method for the determination of phenolics with low concentration in the presence of methanol: A comparative study of real-time monitored reactions". American Journal of Analytical Chemistry 2: 840-848. 2011.

[16] Zakaria, A. J., Ibrahim, N., Ismail, Z. and Mohd, K., "Antibacterial and Phenolic Content of Propolis Produced by Two Malaysian Stingless Bees, Heterotrigona itama and Geniotrigona thoracica". International Journal of Pharmacognosy and Phytochemical Research 8(1): 156-161. 2016.

[17] Vemanaradhya, G., Agarwal, G. and Mehta, D., "Evaluation of chemical composition and efficacy of Chinese propolis extract on Porphyromonas gingivalis and Aggregatibacter actinomycetemcomitans: An in vitro study". Contemporary Clinical Dentistry 3(3): 256-261. 2012.

[18] Shukla, S., "Freeze drying process: A Review". International Journal of Pharmaceutical Sciences and Research 3: 3061-3068. 2011.

[19] Trusheva, B., Popova, M., Bankova, V., Simova, S., Marcucci, M., Miorin, P., Pasin, F. and Tsvetkova, I., "Bioactive Constituents of Brazilian Red Propolis". Evidence-Based Complementary and Alternative Medicine 3(2): 249-254. 2006.

[20] Azwanida, N. "A Review on the Extraction Methods Use in Medicinal Plants, Principle, Strength and Limitation”. Medicinal \& Aromatic Plants 4(3): 1-6. 2015.

[21] Sabir, A. "Respons inflamasi pada pulpa gigi tikus setelah aplikasi ekstrak etanol propolis (EEP) (The Inflammatory Response on Rat Dental Pulp Following Ethanolic Extract of Propolis (EEP) Application)". Dental Journal (Majalah Kedokteran Gigi) 38(2): 77-83. 2005.

[22] Kalogeropoulos, N., Konteles, S., Troullidou, E., Mourtzinos, I. and Karathanos, V. "Chemical composition, antioxidant activity and antimicrobial properties of propolis extracts from Greece and Cyprus”. Food Chemistry 116(2): 452-461. 2009.

[23] Tylkowski, B., Trusheva, B., Bankova, V., Giamberini, M., Peev, G. and Nikolova, A. "Extraction of biologically active compounds from propolis and concentration of extract by nanofiltration". Journal of Membrane Science 348(1-2): 124-130. 2010.

[24] Rebiai, A., Lanez, T. \& Belfar, M. L., "Total polyphenol contents, radical scavenging and cyclic voltammetry of Algerian propolis". International Journal of Pharmacy and Pharmaceutical Sciences 6(1): 395-400. 2014.

[25] Wong, B.Y., Tan, C.P. and Ho, C.W., "Effect of solid-to-solvent ratio on phenolic content and antioxidant capacities of "Dukung Anak" (Phyllanthus niruri)". International Food Research Journal 20(1): 325-330. 2013.

[26] Al-Farsi, M. and Lee, C., "Optimization of phenolics and dietary fibre extraction from date seeds". Food Chemistry 108(3): 977-985. 2008. 
[27] Cacace, J. and Mazza, G., "Mass transfer process during extraction of phenolic compounds from milled berries". Journal of Food Engineering 59(4): 379-389. 2003.

[28] Kähkönen, M. P., Hopia, I., Vuorela, H.J., Rauha, J.P., Pihlaja, K., Kujala, T. S., Heinonen, M. "Antioxidant Activity of Plant Extracts Containing Phenolic Compounds". Journal of Agricultural and Food Chemistry 47 (10): 3954-62. 1999. 